\title{
PENGARUH PELATIHAN PUBLIC SPEAKING TERHADAP KEAKTIFAN BELAJAR PESERTA DIDIK PADA MATA PELAJARAN PENDIDIKAN AGAMA ISLAM
}

\author{
Imam Maulana, Ahmad Haromaini, Faiz Fikri Al Fahmi \\ Universitas Islam Syekh Yusuf Tangerang \\ 1603020036@students.unis.ac,id \\ aharomaini@unis.ac.id \\ ffikri@unis.ac.id
}

\begin{abstract}
This research was conducted with the aim of knowing students in the show much influence the public speaking training has on the learning atctiveness of $8^{\text {th }}$ grade students in the subject of islam religious education at SMP Prima Bakti Kecamatan Panongan Kabupaten Tangerang. The research method used is quantitative research methods with data collection techniques in the form of distributing questionnaires. The respondents of this study were 50 students, based on the results of data processing and discussion, it was concluded that the public speaking training had a strong effect of 44,89\% on the learning activeness of students in the subject of Islamic religious education and in testing the hypothesis $t$ count $>$ t table means that Ho is rejected and accepted ha.
\end{abstract}

Keyword:Training, Public Speaking, Active Learning, Islamic Educatio.

\begin{abstract}
Abstrak
Penelitian ini dilakukan dengan tujuan untuk mengetahui seberapa besar pengaruh Pelatihan Public Speaking terhadap Keaktifan Belajar peserta didik kelas VIII pada mata pelajaran Pendidikan Agama Islam pada SMP Prima Bakti Kecamatan Panongan Kabupaten Tangerang. Metode penelitian yang digunakan adalah metode penelitian kuantitatif dengan teknik pengumpulan data berupa penyebaran angket. Responden penelitian ini berjumlah 50 peserta didik. Berdasarkan hasil olah data dan pembahasan diperoleh kesimpulan bahwasanya pelatihan public speaking berpengaruh kuat sebesar $44,89 \%$ terhadap keaktifan belajar didik pada mata pelajaran Pendidikan Agama Islam. Dan pada pengujian hipotesis $t_{\text {hitung }} t_{\text {tabel }}$ mengandung arti bahwa $\mathrm{H}_{\mathrm{o}}$ ditolak dan diterima $\mathrm{H}_{\mathrm{a}}$.

Kata Kunci: Pelatihan, Publik Speaking, Keaktifan Belajar, Pendidikan Islam.
\end{abstract}




\section{PENDAHULUAN}

Menurut Wiji Suwaro Pendidikan adalah usaha sadar dan terencana untuk mewujudkan suasana proses pembelajaran agar peserta didik secara aktif mengembangkan potensi dirinya sehingga memiliki kekuatan spritual keagamaan, pengendalian diri kepribadian, kecerdasan, ahklak mulia, serta keterampilan yang diperlukan oleh dirinya, bangsa, dan Negara. ${ }^{1}$

Pendidikan adalah hal yang wajib di tempuh oleh setiap manusia dimuka bumi ini, karena dengan pendidiklah manusia dapat memanusiakan dirinya sendiri. Dan melalui pendidiklah manusia dapat mengerti banyak hal yang telah Allah sediakan di muka bumi ini. Oleh sebab itu betapa pentingnya pendidikan untuk umat manusia. Dan dalam pendidikan itu terdapat proses yang di sebut dengan proses belajar mengajar, dalam proses belajar mengajar inilah terjadinya transfer ilmu antara guru kepada peserta didik. Tetapi dalam proses transfer ilmu perlu adanya metode pembelajaran atau cara pembelajran yang digunakan terjadinya proses transfer ilmu tersebut, hal ini diperlukan agar mempermudah peserta didik memahami apa-apa yang disampaikannya oleh gurunya. ${ }^{2}$

Pendidikan adalah hidup Pendidikan adalah segala pengalaman bealajar yang berlangsung dalam segala lingkungan dan sepanjang hidup. Pendidikan adalah segala situasi hidup yang memengaruhi pertumbuhan individu. ${ }^{3}$ Dalam pendidikan rasa ingin tahu manusia yang sangat tinggi mengantarkan manusia harus berusaha mencari tahu atas hal-hal yang hendak diketahuinya. Law of effect menyatakan bahwa tercapainya keadaan yang memuaskan akan memperkuat hubungan antara stimulus dari respons. Law of exercise menyatakan bahwa respon terhadap stimulus dapat diperkuat dengan seringnya respons digunakan dan law of readiness mengajarkan bahwa dalam memberikan respons subjek siap dan disiapkan.

Manusia dibekali potensi untuk dapat memeroleh ilmu pengetahuan. Ilmu pengetahuan sangat berarti baginya. Pengetahuann akan dapat membantunya memahami hal-hal di luar dirinya maupun yang berhubungan langsung dengannya. Islam mendukung manusia memeroleh ilmu pengetahuan dengan mewajibkan mencari ilmu. Karena bagaimana pun melalui ilmu yang dimiliki manusia, ia menjadi mulia, memeroleh kedudukan terhormat karena telah mampu memaksimalkan pengetahuan yang dimilikinya. ${ }^{4}$ Proses mendapatkan ilmu pengetahuan yang ditempuh manusia dapat dilalui dengan cara belajar dan

\footnotetext{
Ke II, h. 176

${ }^{1}$ Wiji Suwarno, Dasar-dasar Ilmu Pendidikan, ( Jogjakarta: Ar Ruzz Media, 2017,Cet,

${ }^{2}$ Titarahardja umar, Pengantar Pendidikan, Jakarta, PT Rineka Cipta,2005, h.114

${ }^{3}$ Redja Muyaharjo, Pengantar Pendidikan: Sebuah Study Awal Tentang Dasar-Dasar Pendidikan Pada Umumnya dan Pendidikan di Indonesia, Jakarta: RajaGrafindo Persada,2009) h.3

${ }^{4}$ Ahmad Haromaini, 'Manusia Makhluk Pembelajaran', Islamika Unis, 405.
} 
menggunakan beberapa metode pembelajaran yang disampaikan salah satunya dengan melatih peserta didik memiliki kompetensi public speaking.

Public speaking merupakan seseorang yang memiliki kemampuan untuk mempengaruhi orang serta menyampaikan informasi yang menarik di depan orang banyak seperti pemateri dalam seminar. Sukses atau tidaknya public speaking di sebabkan oleh bagaimana ia dapat mengkomunikasikan seluruh informasi tentang apa yang disampaikannya. ${ }^{5}$

Komunikasi manusia tidak hanya terjadi antar personal dan interpersonal akan tetapi juga terjadi dalam yang suatu kelompok. Artinya seseorang yang berbicara didepan orang banyak membutuhkan keahlian tertentu, karena pemahaman seseorang pasti akan berbeda-beda. Orang yang tidak bisa berdiri dan berbicara didepan banyak secara tidak langsung mereka akan mengalami demam panggung atau tidak percaya diri sehingga pesan yang akan disampaikan akan sulit diterima oleh pendengar atau audiens. Oleh sebab itu, kemampuan public speaking itu bukanlah bawaan sejak lahir, namun kompetensi ini didapatkan berdasarkan kemauan yang keras untuk belajar dan mencoba.

Tidak dapat dipungkiri bahwa kemampuan untuk berbicara didepan umum atau yang lebih sering disebut dengan public speaking merupakan kemampuan yang wajib dimiliki oleh seorang guru.karena seorang peserta didik harus dituntut memiliki public speaking yang baik dan meningkatkan keaktifan belajar peserta didik. $^{6}$ sebagaimana firman Allah yang terdapat mengenai kemampuan untuk berbicara atau berkomunikasi yang dimiliki oleh seseorang:

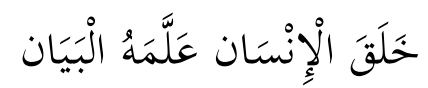

Artinya: "Dan menciptakan manusia, yang mengajarinya pandai berbicara" (Q.S Ar-Rahman [55]:3-4)

Ayat diatas dijelaskan, bahwa Allah mengajarkan kepada setiap kaum bahasa kepada mereka, yang mereka gunakan untuk berkomunikasi Rasa takut untuk berbicara didepan umum atau didepan kelas sering kali dialami oleh para peserta didik. Peserta didik sering kali dihadapkan pada tugas untuk melakukan presentasi didalam kelas. Beberapa pernyataan speserta didik tersebut menandakan kemampuan public speaking peserta didik yang masih kurang optimal.

Keaktifan peserta didikpun cukup berperan penting akan tetapi tidak dapat dipungkiri pula ada beberapa peserta didik yang masih dibawah rata-rata tingkat

\footnotetext{
${ }^{5}$ Fitriana utami, Public Speaking, Kunci Sukses Berbicara Didepan Public Teori Dan Praktik, ( Jakarta:Pustaka Pelajar, 2003), hal. 108-109

${ }^{6}$ Widayanto Bintang, Powerfull Public Speaking, ( Yogyakarta: Andi, 2014 ), h.7
} 
belajarnya dalam proses pembelajarannya,maka dari itu public speaking guru itu penting untuk cara penyampaianya dengan secara fasih dan sering terjadi kejenuhan yang timbul dalam diri peseta didik, karena peserta didik pasif dalam proses pembelajaran. ${ }^{7}$ Lalu yang menjadi pertanyaan adalah bagaimana Pengaruh Pelatihan Public Speaking yang digunakan guru dalam meningkatkan keaktifan belajar kelas VIII pada mata pelajaran Pendidikan Agama Islam di SMP Prima Bakti Kecamatan Panongan Kabupaten Tangerang dan Apa Faktor-faktor penghambat pelatihan public speaking peserta didik kelas VIII pada mata pelajaran Pendidikan Agama Islam di SMP Prima Bakti Kecamatan Panongan Kabupaten Tangerang?

Penelitian ini diharapkan bertujuan untuk mengetahui Pelatihan Public Speaking yang digunakan guru dalam meningkatkan keaktifan belajar pada mata pelajaran Pendidikan Agama Islam di sekolah SMP Prima Bakti Kabupaten Tangerang dan untuk mengetahui Faktor-faktor penghambat pelatihan public speaking peseta didik kelas VIII pada mata pelajaran Pendidikan Agama Islam di sekolah SMP Prima Bakti Kabupaten Tangerang.

\section{METODE PENELITIAN}

1. Desain Penelitian

Desain penelitian yang digunakan dalam penelitian ini adalah menggunakan metode deskriptif kuantitatif, yaitu jenis penelitian yang menghasilkan penemuanpenemuan yang dapat dicapai (diperoleh) dengan menggunakan prosedurprosedur statistic atau cara-cara lain dari kuantifikasi (pengukuran).

Metode penelitian kuantitatif dapat diartikan sebagai metode penelitian yang berdasarkan pada filsafat positivism, digunakan untuk meneliti pada populasi atau sampel tertentu, teknik pengambilan sampel pada umumnya dilakukan secara random, pengumpulan data menggunakan instrumen penelitian, analisis data bersifat kuantitatif/ statistik dengan tujuan untuk menguji hipotesis yang telah ditetapkan ${ }^{8}$.

Dalam penelitian ini yang merupakan variabel bebas adalah Pelatihan Public Speaking (variabel X) sedangkan variabel terikat adalah Keaktifan Belajar Peserta didik (variabel Y) jenis penelitian ini menguji seberapa besar pengaruh pelatihan public speaking terhadap keaktifan belajar peserta didik di kelas VIII.

\footnotetext{
${ }^{7}$ Sinar, Metode Active Learning,( Yogyakarta: Drono Sardonoharjo,2018), Cet,ke 1.h.8

${ }^{8}$ Sugiono, Metode Penelitian kuantitatif, kualitatif, dan R\&D,(Bandung : Alfabeta,2017), h. 2
} 


\section{Populasi}

Populasi adalah wilayah generalisasi yang terdiri atas objek/ subjek yang mempunyai kualitas dan karakteristik tertentu yang ditetapkan oleh peneliti untuk di pelajari dan kemudian ditarik kesimpulan, ${ }^{9}$ adapun populasi target dalam penelitian adalah peserta didik di kelas VIII SMP Prima Bakti Kab.Tangerang. Dalam penelitian ini teknik pengambilan sampelnya yang digunakan adalah teknik Random sampling, yaitu pengambilan pengambilan sampel berdasarkan tujuan penelitian, dan sampel yang akan diambil yaitu kelas VIII, Sebanyak 3 kelas, dari $\mathrm{A}, \mathrm{B}$,dan $\mathrm{C}$ yang berjumlah 92 peserta didik, akan tetapi di sini peneliti akan membahas secara terperimci tidak secara global, yaitu meneliti kelas VIII yang berjumlah 92 Peserta didik.

3. Sampel

Sampel adalah bagian dari jumlah dan karakteristik yang dimiliki oleh populasi tersebut. Bila populasi besar, dan peneliti tidak mungkin mempelajari semua yang ada pada populasi, Misalnya karena keterbatasan dana, tenaga dan waktu, maka peneliti dapat menggunakan sampel yang diambil dari populasi itu. Apa yang dipelajari dari sampel itu, kesimpulannya akan dapat diberlakukan untuk populasi. ${ }^{10}$ Untuk itu sampel yang diambil dari populasi harus betul-betul representative ( mewakili ).

\section{Alat Pengumpulan Data}

Untuk mendapatkan data yang teliti maka penelitian menggunakan alat pengumpulan data sebagai berikut:

Sebagai alat pengumpulan data harus tepat dan memungkinkan diperolehnya data yang objektif. Data yang dikumpulkan dalam penelitian ini adalah data kuantitatif. Alat pengumpulan data yang digunakan melalui daftar pernyataan yang diperoleh dari angket yang disebarkan kepada responden.

\section{Teknik Analisis Data}

Dalam penelitian kuantitatif, analisis data merupakan kegiatan setelah data dari seluruh responden terkumpul. Kegiatan analisis data ialah mengelompokkan data berdasarkan variabel dan jenisnya, mentabulasi data berdasarkan variabel dan seluruh jumlah responden, menyajikan data yang telah diperoleh, melakukan perhitungan untuk menjawab rumusan masalah, dan melakukan perhitungan untuk hipotesis yang telah diajukan. Untuk menganalisis data yang sudah ada, peneliti

\footnotetext{
${ }^{9}$ Sugiono, Metode Penelitian Kuantitatif, kualitatif, dan R\&D, ( Bandung : Penerbit Alfabeta, 2017), Cet. 25, h. 80

${ }^{10}$ Sugiyono, Metode Penelitian Kuantitatif, kualitatif, dan R\&D, (Bandung : Penerbit Alfabeta, 2017), cet. 25, h. 80
} 
akan menganalisis data dengan statistik deskriptif, setelah data yang diperlukan terkumpul dari penyebaran angket yang sudah diberikan kepada Peserta didik di kelas VIII SMP Prima Bakti Kecamatan Panongan Kabupaten Tangerang.

\section{HASIL DAN PEMBAHASAN}

Menurut Arifin yang dikutif Abd Azis Albone mengatakan bahwa pendidikan Islam adalah suatu proses pendidikan yang mencakup seluruh aspek kehidupan yang dibutuhkan hamba Allah Swt. (anak didik) dengan pedoman pada ajaran Islam. Pendidikan Islam juga merupakan usaha dari orang dewasa ( muslim ) yang bertakwa, yang secara sadar mengarahkan dan membimbing pertumbuhan dan perkembangannya. Dalam konsep pendidikan Islam, guru adalah spiritual father atau bapak rohani bagi murid. Gurulah yang memberi santapan jiwa dengan ilmu, pendidikan Akhlak dan membenarkannya, maka menghormati guru berarti penghormatan terhadap anak-anak pula. Pendidikan Islam itu adalah proses pembentukan individu berdasarkan ajaran Islam untuk mencapai derajat tinggi sehingga mampu menuaikan fungsi kekhalifahannya dan berhasil mewujudkan kebahagiaan dunia dan akhirat. ${ }^{11}$

Public Speaking adalah keterampilan berbicara didepan umum sangat diperlukan guna meningkatkan diri diera global ini. Dengan memiliki kemampuan berbicara didepan umum skill yang anda miliki akan menjadikan anda orang yang banyak dicari karena memiliki keahlian. Namun dari itu, public speaking juga memiliki manfaat yang sangat luar biasa. Meningkatkan professional memiliki kemampuan public speaking akan meningkatkan professionalisme.Meski public speaking ini banyak menuntut keaktifan peserta didik,tetapi public speaking ini tetap jngan ditinggalkan begitu saja dalam kegiatan belajar. Apalagi dalam pendidikan seorang guru harus mengajar dengan ceramah agar seorang peserta didik supaya aktif dalam pembelajaran.Dengan demikian dapat dipahami bahwa public speaking itu sangat penting untuk seorang peserta didik

Keaktifan Belajar adalah hal atau keadaan dimana peserta didik dapat aktif. Keaktifan pesertaa didik dalam hal ini dapat dilihat dari kesungguhan mereka mengikuti pelajaran. Peserta didik yang kurang aktif akan ditunjukan oleh beberapa kasus di kelas seperti kurang adanya gairah belajar, malas, cemderung ngantuk, enggan mengikuti pelajaran, cenderung ingin ijin keluar kelas dengan alasan ke belakang, tidak konsentrasi, ngobrol dengan teman-

\footnotetext{
${ }^{11}$ Abd Aziz Albone, Pendidikan Agama Islam Dalam Perspektif Multikulturalisme, ( Jakarta: Balai Penelitian dan Pengembangan Agama, 2009), h.34
} 
temannya, mengerjakan tugas pada mata pelajaran lain, sedang jam pelajaran saat ini tengah berlangsung, dan sebagainya. ${ }^{12}$

Maka guru perlu mencari cara untuk meningkatkan keaktifan peserta didik.Keaktifan merupakan motor dalam kegiatan belajar, peserta didik dituntut untuk aktif. Keaktifan belajar dipengaruhi oleh banyak faktor. Baik yang datang dari dalam diri peserta didik maupun yang datang dari luar diri peserta didik. Keaktifan peserta didik dalam kegiatan belajar tidak lain adalah untuk mengkontruksikan pengetahuan mereka sendiri. Mereka aktif membangun pemahaman atas oersoalan atau segala sesuatu yang mereka hadapi dalam proses pembelajaran. Dapat disimpulkanan bahwa adanya pelatihan public speaking ini membantu gairah belajar peserta didik dan berperan aktif dalam proses belajar mengajar dikelas, maka dari itu bimbingan belajar yang diberikaan guru FAI selanjutnya adalah melakuakan peninjauan ( melakukan apersepsi dan refleksi) guna mengingat dan mengihtiarkan kembali apa yang telah dipelajari. keaktifan peserta didik dalam belajar merupakan segala kegiatan yang bersifat fisik maupun non fisik peserta didik dalam proses kegiatan belajar mengajar yang optimal sehingga dapat menciptakan susasana kelas ,menjadi kondusif.

${ }^{12}$ Sinar, Metode Active Learning...,Cet ke-1, h. 8-9 
Qiro'ah $\mid$ Jurnal Pendidikan Agama Islam

Vol. 11 No. 1 2021|https://ejurnal.iiq.ac.id/index.php/qiroah P-ISSN: 2085-0115 E-ISSN: 2656-3819

DOI: https://doi.org/10.33511/qiroah.v11n1.39-51

\section{Rancangan Penguji Hipotesis}

a. Regresi Linier Sederhana

Analisis regresi linier sederhana digunakan untuk menjawab hipotesis pertama dan kedua dan mengetahui pengaruh secara persial antara Variabel bebas (X) dan Variabel terikat (Y). persamaan analisis sederhana sebagai berikut: Y- $(b x)=-23,50$

b. Koefisien Korelasi

Untuk mengetahui korelasi antara Variabel X dan Y tersebut, maka harus dihitung nilai koefisien " $\mathrm{r}_{\mathrm{xy}}$ ", yaitu sebagai berikut:

Koefesien Korelasi ( $r$ ):

$$
r_{x y}=\frac{\mathrm{n} \Sigma \mathrm{xy}_{-}(\Sigma \mathrm{x})(\Sigma \mathrm{y})}{\sqrt{\left(n \Sigma x^{2}-(\Sigma x)^{2}\left(N \Sigma y^{2}-(\Sigma y)^{2}\right)\right.}}
$$

Hasil dari rumus tersebut adalah 0,67 .

c. Koefisien Determinasi

Jadi dapat diketahui bahwa pelatihan public speaking 44,89\% berpengaruh terhadap keaktifan belajar peserta didik pada mata pelajaran Pendidikan Agama Islam.

Frekuensi Data Pelatihan Public Speaking

\begin{tabular}{|c|c|c|c|}
\hline No & Interval Kelas & $\begin{array}{c}\text { Frekuensi } \\
\text { Absolut }\end{array}$ & $\begin{array}{c}\text { Presentase } \\
\mathbf{( \% )}\end{array}$ \\
\hline 1 & $22-25$ & 1 & 2 \\
\hline 2 & $26-29$ & 0 & 0 \\
\hline 3 & $30-33$ & 2 & 4 \\
\hline 4 & $34-38$ & 2 & 4 \\
\hline 5 & $39-42$ & 19 & 38 \\
\hline 6 & $43-46$ & 14 & 28 \\
\hline 7 & $47-50$ & 12 & 24 \\
\hline & Jumlah & 50 & 100 \\
\hline
\end{tabular}

Dari tabel di atas diperoleh keterangan bahwa data terkecil adalah 22 dan data terbesar adalah 50, rentang (R) 28 , banyaknya kelas (B) 7, panjang kelas interval (P) 4, modus $\left(\mathrm{M}_{\mathrm{o}}\right)$ 41,58, median $\left(\mathrm{M}_{\mathrm{e}}\right)$ 43,634 dan mean $(\mathrm{X})$ 42,64. Data tersebut dapat diperoleh melalui perhitungan-perhitungan dengan memakai aturan Sturgues. 
Qiro'ah| Jurnal Pendidikan Agama Islam

Vol. 11 No. 1 2021| https://ejurnal.iiq.ac.id/index.php/qiroah P-ISSN: 2085-0115 E-ISSN: 2656-3819

DOI: https://doi.org/10.33511/qiroah.v11n1.39-51

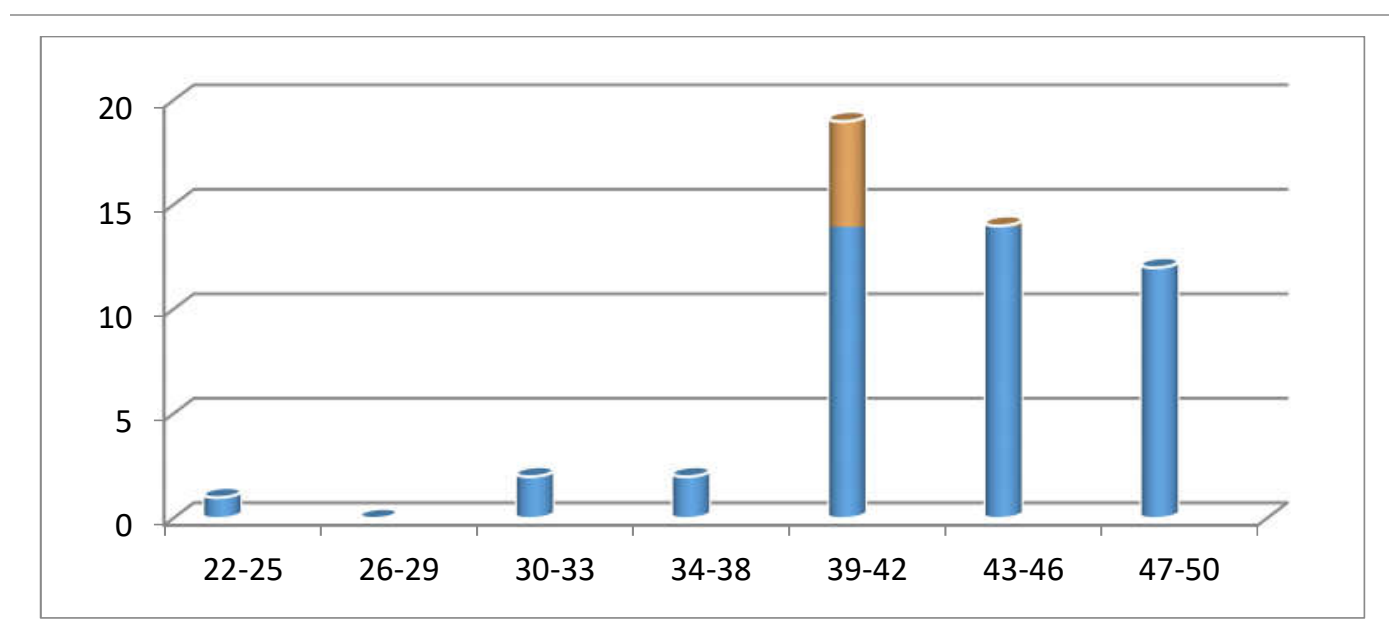

Grafik 1

pelatihan Public Speaking

Frekuensi Data Keaktifan Belajar

\begin{tabular}{|c|c|c|c|}
\hline No. & Interval Kelas & Frekuensi Absolut & $\begin{array}{c}\text { Presentase } \\
\mathbf{( \% )}\end{array}$ \\
\hline 1 & $22-24$ & 1 & $2 \%$ \\
\hline 2 & $25-27$ & 0 & $0 \%$ \\
\hline 3 & $28-30$ & 0 & $0 \%$ \\
\hline 4 & $31-33$ & 6 & $12 \%$ \\
\hline 5 & $34-38$ & 26 & $52 \%$ \\
\hline 6 & $39-43$ & 11 & $22 \%$ \\
\hline 7 & $44-46$ & 6 & 12 \\
\hline & Jumlah & 50 & $100 \%$ \\
\hline
\end{tabular}

Dari tabel di atas diperoleh keterangan bahwa data terkecil adalah 22 dan data terbesar adalah 46, rentang (R) 24 , banyaknya kelas (B) 7, panjang kelas interval (P) 3modus $\left(\mathrm{M}_{\mathrm{o}}\right)$ 35,21, median $\left(\mathrm{M}_{\mathrm{e}}\right)$ 35,75 dan mean $(\mathrm{Y})$ 37,58. Data tersebut dapat diperoleh melalui perhitungan-perhitungan dengan memakai aturan Sturgues. 
Qiro'ah| Jurnal Pendidikan Agama Islam

Vol. 11 No. 1 2021| https://ejurnal.iiq.ac.id/index.php/qiroah P-ISSN: 2085-0115 E-ISSN: 2656-3819

DOI: https://doi.org/10.33511/qiroah.v11n1.39-51

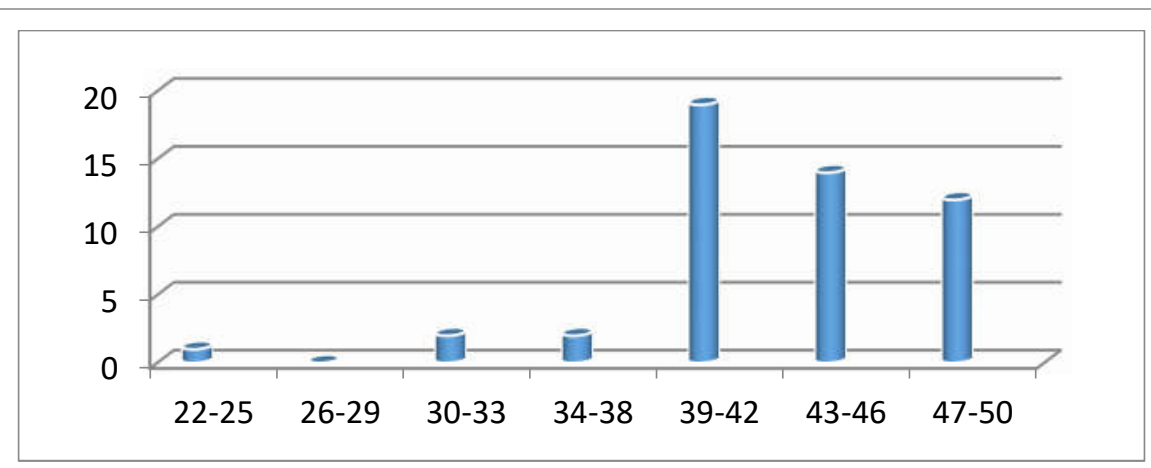

Grafik 4.2

Frekuensi Data Keaktifan Belajar

Selanjutnya untuk mengetahui seberapa besar hubungan antar variabel tersebut dapat dihitung dengan koefesien determinasi, yaitu dengan mengkuadratkan nilai koefesien korelasi " $r$ " kemudian dikalikan dengan 100\%. Berikut perhitungannya:

\section{Koefisien Determinasi}

$$
\begin{aligned}
\mathrm{KD} & =\mathrm{r}^{2} \times 100 \% \\
& =(0,67)(0,67) \times 100 \% \\
& =0,4489 \times 100 \% \\
& =44,89 \%
\end{aligned}
$$

Jadi dapat diketahui bahwa pelatihan public speaking 44,89\% berpengaruh terhadap keaktifan belajar peserta didik pada mata pelajaran Pendidikan Agama Islam.

\section{c.2. Pengujian Hipotesis}

Penguji hipotesis ini untuk mengetahui apakah hipotesis yang diajukan diterima atau ditolak. Jika nilai $\mathrm{t}_{\text {hitung }}{ }^{>} \mathrm{t}_{\text {tabel }}$ maka hipotesis diterima namun apabila $\mathrm{t}_{\text {hitung }}<\mathrm{t}_{\text {tabel }}$ maka hipotesis ditolak atau tidak diterima.

\section{c.3. Statistik Uji (Uji t)}

Penguji hipotesis ini menggunakan rumus sebagai berikut:

$$
\begin{aligned}
& \mathrm{t}=\frac{r \sqrt{n-2}}{\sqrt{1-r^{2}}} \\
& \mathrm{t}=0,67 \sqrt{\frac{50-2}{1-0,448}} 9 \\
& \mathrm{t}=0,67 \sqrt{\frac{48}{0,5511}} \\
& \mathrm{t}=0,67 \sqrt{87,09} \\
& \mathrm{t}=(0,67)(9,33)
\end{aligned}
$$


$\mathrm{t}=6,2511$

Dari hasil di atas, maka nilai $t_{\text {hitung }}$ adalah 6,2511 . Selanjutnya yaitu nilai $\mathrm{t}_{\text {tabel }}$ pada taraf signifikan 0,05 atau $5 \%$ dan $0,01(1 \%) \mathrm{dk}=\mathrm{n}-2$ jadi, $50-2=48$ maka nilai $t_{\text {tabel }}$ dari 48 adalah 2,011 dan 2,682 Dengan demikian hasil perhitungan tersebut diketahui bahwa nilai $t_{\text {hitung }}>t_{\text {tabel }}$ yang artinya hipotesis yang diajukan diterima.Berarti terdapat pengaruh pelatihan public speaking Terhadap keaktifan belajar peserta didik.

Pada taraf signifikan $0,05(5 \%) \mathrm{t}_{\text {hitung }} 3,48>\mathrm{t}_{\text {tabel }} 2,035$ begitu pula diambil dari taraf signifikan 0,01 (1\%) $\mathrm{t}_{\text {hitung }} 6,2511>\mathrm{t}_{\text {tabel }} 2,011$.

Berdasarkan hasil uji coba penelitian tersebut terdapat pengaruh yang positif dengan adanya pelatihan public speaking terhadap Keaktifan belajar peserta didik meskipun pengaruhnya masih dalam taraf kuat.

Sedangkan hasil dari korelasi Product Moment terdapat pengaruh pelatihan public speaking terhadap Keaktifan belajar peserta didik sebesar 0,67 dan ini masuk dalam interval koefisien 0,60 - 0,799 yang artinya masuk dalam peranan tingkat kuat. Demikian juga dengan perhitungan koefisien determinasi dengan kontribusi sebesar $45 \%$ berpengaruh terhadap Keaktifan belajar peserta didik dan 55\% Keaktifan belajar peserta didik dipengaruhi oleh faktor lainnya yang tidak diteliti dalam penelitian ini.

Untuk mengetahui tingkat signifikan dilakukan penguji hipotesis yang menggunakan uji $t_{\text {hitung }}$ Pengaruh Pelatihan Public Speaking Terhadap keaktifan belajar peserta didik, yaitu dengan membandingkan hasil perhitungan $t_{\text {hitung }}$ dengan $t_{\text {tabel }}$ distribusi nilai. Pada taraf signifikan 5\% dan $1 \%$ hasil yang telah didapat dari $t_{\text {hitung }}$ adalah 6,2511 dan dari $t_{\text {tabel }}$ adalah 2,011 dan 2,682. Dengan demikian $\mathrm{H}_{\mathrm{a}}$ yang menyatakan bahwa pengaruh Pelatihan Public Speaking Terhadap keaktifan belajar peserta didik kelas VIII pada mata pelajaran PAI di sekolah SMP Prima Bakti Kabupaten Tangerang diterima dan hipotesis $\mathrm{H}_{\mathrm{o}}$ ditolak.

\section{KESIMPULAN}

Dari hasil penelitian yang telah peneliti lakukan di Sekolah SMP Prima Bakti Kecamatan Panongan Kabupaten Tangerang, maka dapat diambil kesimpulan bahwa:

Terdapat Pengaruh yang kuat antara pelatihan public speaking terhadap keaktifan belajar peserta didik kelas VIII pada mata pelajaran PAI di Sekolah SMP Prima Bakti Kecamatan Panongan Kabupaten Tangerang. Hal ini telah dibuktikan dengan perhitungan korelasi product moment yang diperoleh hasilnya 0,67. Ini menunjukkan betapa pentingnya pelatihan public speaking yang tepat dalam menerapkan dikelas.Antara pelatihan public speaking (variabel X) dengan keaktifan belajar (variabel Y) terdapat korelasi yang kuat, hal ini juga kuat dengan didapatnya $\mathrm{T}_{\text {hitung }} 6,2511$ lebih besar $\mathrm{T}_{\text {tabel }}$ yaitu 2,011. Dari hasil penelitian 
Qiro'ah $\mid$ Jurnal Pendidikan Agama Islam

Vol. 11 No. 1 2021|https://ejurnal.iiq.ac.id/index.php/qiroah P-ISSN: 2085-0115 E-ISSN: 2656-3819

DOI: https://doi.org/10.33511/qiroah.v11n1.39-51

dengan perhitungan koefisien determinasi dapat diketahui pelatihan public speaking berpengaruh terhadap keaktifan belajar sebesar $45 \%$ dan selebihnya $55 \%$ dipengaruhi oleh faktor-faktor lain diantara faktor lingkungan, dan fasilitas sekolah lainnya yang tidak diteliti. Jadi $\mathrm{H}_{\mathrm{o}}$ tidak memiliki pengaruh terhadap Keaktifan peserta didik kelas VIII pada mata Pelajaran Pendidikan Agama Islam di SMP Prima Bakti Kecamatan Panongan Kabupaten Tangerang ditolak dan $\mathrm{H}_{\mathrm{a}}$ diterima. 
Qiro'ah $\mid$ Jurnal Pendidikan Agama Islam

Vol. 11 No. 1 2021|https://ejurnal.iiq.ac.id/index.php/qiroah P-ISSN: 2085-0115 E-ISSN: 2656-3819

DOI: https://doi.org/10.33511/qiroah.v11n1.39-51

\section{DAFTAR PUSTAKA}

Abidin, Yunus. Penelitian Pendidikan Dalam Gamintan Pendidikan. 2011.

Ahmadi, Rulam. Pengantar Pendidikan. Yogyakarta: AR-Ruzz Media, 2014.

Widayanto, Bintang. PowerFull Public Speaking. Yogyakarta : Andi, 2014.

Cangara, Hafied. Pengantar Ilmu Komunikasi. Jakarta: Raja Grafindo Persada, 2012.

Darajat, Zakiyah. Ilmu Pendidikan Islam. Jakarta : Bumi Aksara, 1992.

Darmadi, Pengembangan model metode pembelajaran dalam Dinamika Belajar Siswa, 2012.

Dimyati \& Mujiono. Belajar dan Pembelajaran. Jakarta : Pt Rinekacipta, 2009.

Effendi, Onong Uchjana. Ilmu-Ilmu Komunikasi. Bandung: Remaja Rosada Karya, 2007.

Fujishin, Randy. Smart Public Speaker Seni Berbicara Di Muka Umum. Jogyakarta: Diglossia Media, 2009.

Haromaini, Ahmad. Manusia Makhluk Pembelajaran. Islamika Unis, 405.

Hawi, Akmal. kompetensi Guru PAI. Jakarta: PT Raja Grafindo Persada, 2013.

Hidayatulloh, Syarif Furqon. Pendidikan Agama Islam Pada Perguruan Tinggi Umum. Bogor: IPB Press., 2018.

Imron, Ali. Manajemen Peserta Didik Berbasis Sekolah. Jakarta: Pt Bumi Aksara, 2011.

Jalaludin, Rahmat. Retorika Modern Pendekatan Praktis. Bandung; Remaja Rosda Karya, 1994.

Mujib, Abdul. Ilmu Pendidikan Islam. Jakarta: Prenada Media Group, 2008.

Mulyana, Dedy. Ilmu Komunikasi Suatu Pengantar. Jakarta : Remaja Rosda Karya, 2008.

Nurudin. Pengantar Komunikasi Massa. Jakarta: PT. Raja Grafindo Persada, 2007.

Oli, Helena. Public Speaking, Cet Ketiga. Jakarta: Pt Macana Jaya Cemerlang, 2008. 
Qiro'ah $\mid$ Jurnal Pendidikan Agama Islam

Vol. 11 No. 1 2021|https://ejurnal.iiq.ac.id/index.php/qiroah P-ISSN: 2085-0115 E-ISSN: 2656-3819

DOI: https://doi.org/10.33511/qiroah.v11n1.39-51

Sinar. Metode Active Learning. Yogyakarta: Drono Sardonoharjo, 2018.

Sudjana, Nana. Penilaian Hasil Proses Belajar Mengajar. Bandung: Remaja Rosdakarya, 2007.

Sugiono. Metode Penelitian Kuantitatif, kualitatif, dan R\&D. Bandung : Penerbit Alfabeta, 2017.

Sugiono. Statistik untuk penelitian. Bandung : Alfabeta, 2015.

Tadjab. Perbandingan Pendidikan. Surabaya: Karya Abadi toma, 1994.

Utami, Fitriana. Public Speaking, Kunci Sukses Berbicara Di Depan Publik Teori Dan Praktik. Jakarta: Pustaka Pelajar, 2003.

Zuhri, Saifuddin. Public Speaking. Yogyakarta: Graha Ilmu, 2020. 